\title{
Erratum to: The Method of Generalized Ordered Probit with Selectivity: Application to Marital Happiness
}

\author{
Karen Leppel
}

Published online: 25 July 2014

(c) Springer Science+Business Media New York 2014

\section{Erratum to: J Fam Econ Iss}

\section{DOI 10.1007/s10834-014-9407-2}

The original version of this article unfortunately contained errors in displaying the equations. The presentation of some equations under sections "Mathematical Development" and "Appendix" were incorrect. The corrected equations are given below:

\section{Correction 1}

In the "Generalized Ordered Probit Model with Selectivity" subsection of the "Mathematical Development" section, multiple lines of text are missing. For clarity, all four cases are shown below in their entirety.

Case 1: $\quad \operatorname{Pr}(M=1$ and $S=1)$

$=\operatorname{Pr}\left(u>-Z \gamma\right.$ and $\left.\varepsilon \leq-X \beta_{1}\right)$

$=\Phi_{1}\left(-X \beta_{1}\right)-\Phi_{2}\left(-Z \gamma,-X \beta_{1}, \rho\right)$
Case 2: $\quad \operatorname{Pr}(M=1$ and $S=2)$

$$
\begin{aligned}
= & \operatorname{Pr}\left(u>-Z \gamma \text { and }-X \beta_{1} \leq \varepsilon \leq-X \beta_{2}\right) \\
= & {\left[\Phi_{1}\left(-X \beta_{2}\right)-\Phi_{1}\left(-X \beta_{1}\right)\right] } \\
& -\left[\Phi_{2}\left(-Z \gamma,-X \beta_{2}, \rho\right)-\Phi_{2}\left(-Z \gamma,-X \beta_{1}, \rho\right)\right]
\end{aligned}
$$

Case 3: $\operatorname{Pr}(M=1$ and $S=3)$

$=\operatorname{Pr}\left(u>-Z \gamma\right.$ and $\left.\varepsilon \geq-X \beta_{2}\right)$

$=1-\Phi_{1}(-Z \gamma)-\Phi_{1}\left(-X \beta_{2}\right)$

$$
+\Phi_{2}\left(-Z \gamma,-X \beta_{2}, \rho\right)
$$

Case 4: $\quad \operatorname{Pr}(M=0)=\operatorname{Pr}(u \leq-Z \gamma)=\Phi_{1}(-Z \gamma)$

\section{Correction 2}

In the Appendix, part of the first line of Case "s" is missing. The beginning of Case " $\mathrm{s}$ " should read as follows.

Case s: $\quad \operatorname{Pr}(M=1$ and $S=s)$

The online version of the original article can be found under doi:10. 1007/s 10834-014-9407-2.

K. Leppel $(\bowtie)$

School of Business Administration, Widener University, One

University Place, Chester, PA 19013, USA

e-mail:kleppel@widener.edu 